\title{
JOSEP MANUEL UDINA I COBO, MEDIEVALISTA
}

\author{
Jaume Mensa i Valls \\ Universitat Autònoma de Barcelona
}

El jueves 3 de junio de 2010, a las 11:30 de la mañana, el profesor Josep Ml. Udina i Cobo pronunció su Darrera lliçó magistral, con el título L'ésser mai no acabat que som, en la Facultat de Filosofia i Lletres de la Universitat Autònoma de Barcelona. ${ }^{1}$ Con ella culminaba una larga y fructífera carrera docente y alcanzaba la jubilación.

Los lectores de la Revista Española de Filosofía Medieval conocen bien a Josep Ml. Udina: Es miembro fundador de la Sociedad de Filosofía Medieval y forma parte desde entonces (1990) de su consejo directivo; ha participado en los congresos que cada cuatro años viene organizando; ${ }^{2}$ colabora con nuestra Revista (pertenece a su equipo de redacción) y en ella han aparecido reseñas de algunas de sus publicaciones.

Josep Manuel Udina i Cobo (Barcelona, 9 noviembre de 1939) estudió el Bachillerato en los jesuítas de Sarrià (Barcelona). Más tarde, en 1956, ingresó en la Compañía de Jesús, estudió Humanidades, cursó las licenciaturas en Filosofía (1963) y Teología (1970) en las respectivas facultades pontificias de Sant Cugat del Vallès. ${ }^{3}$ Obtuvo también la licenciatura civil en filosofía, en la Universidad de Barcelona (1966), con una tesina sobre la Fenomenología del Espíritu de Hegel, dirigida por el Dr. Alfonso Álvarez Bolado. ${ }^{4}$ Se doctoró en la misma Universidad de Barcelona con una tesis sobre Ernst Bloch, dirigida por el Dr. Miquel Siguan i Soler, en el año 1976. ${ }^{5}$ Cuatro años antes (1972), cuando estaba realizando una estancia de estudios en Alemania, abandonó la Compañía de Jesús.

1 Darrera lliçó magistral de Josep Manuel Udina: L'ésser mai no acabat que som. Acte d'homenatge, 3 de juny de 2010, Bellatera, UAB, 2010, 33 p. En esta publicación el lector interesado puede hallar una lista actualizada de las publicaciones del prof. Udina. Con el mismo objetivo podrá verse la entrada Udina i Cobo, Josep Manuel, en A. Heredia Soriano (ed.), Hombres y documentos de la filosofía española, Madrid, CSIC, en proceso de publicación.

2 «El cur Deus homo anselmiano: ratio fidei y autolimitación de la razón», en DD. AA., Actas del I Congreso Nacional de Filosofía Medieval, Zaragoza, SOFIME, 1992, p. 475-483; «Ejemplificación medieval de la interrelación teoría-praxis. (De Escoto Eriúgena a Anselmo de Canterbury, con Agustín de fondo», en DD. AA., Actas del II Congreso Nacional de Filosofía Medieval, Zaragoza, SOFIME, 1996, p. 499-512; «Ernst Bloch y el averroísmo de su Avicena y la izquierda aristotélica», en DD. AA., Averroes y los averroísmos. Actas del III Congreso de Filosofía Medieval, Zaragoza, SOFIME, 1999, p. 371-385; Ni contigo ni sin ti: la filosofía y la teología de Maimónides en relación a Aristóteles y al tema de la creación, en DD.AA., Maimónides y el pensamiento medieval: VIII centenario de la muerte de Maimónides. Actas del IV Congreso Nacional de Filosofía Medieval, Córdoba, Universidad, 2007, p. 75-100; De Gelasio (I) a Gelasio (II), o de Iglesia mendigo a Iglesia príncipe, DD.AA., El pensamiento político en la Edad Media, Madrid, Fundación Ramón Areces, 2010, p. 65-92.

3 La tesina de teología trataba de La historia de la fe y de la comunidad cristianas según la filosofía de la historia de G.W.F. Hegel, Sant Cugat del Vallès, 1970, 47 págs.

4 Aproximación a la «Fenomenología del Espíritu» de Hegel: la historia del concepto y el concepto de la historia, Universitat de Barcelona, 1966, 353 págs.

5 La constitución utópica de lo humano. Introducción y anotaciones críticas a la filosofía de Ernst Bloch, Universitat de Barcelona, 1976, 3 vols., 824 págs. 
Josep Ml. Udina ha dedicado prácticamente toda su vida profesional a la docencia e investigación en el Departament de Filosofia de la Universitat Autònoma de Barcelona: desde 1972 hasta su jubilación al acabar el curso 2009-2010. Durante los primeros seis años combina la docencia universitaria con tareas editoriales, especialmente en la Enciclopèdia Catalana (es redactor de la misma y autor de diversas voces sobre filosofía y teología), ${ }^{6}$ después (1978) la ejerce a plena dedicación, y más tarde (1985) obtiene la plaza de Profesor Titular.

$\mathrm{Su}$ docencia durante todos estos cursos ha sido muy extensa e intensa. Cada dos años ha impartido alternativamente un curso monográfico sobre Hegel y otro sobre la filosofía española del siglo XX, además de las tres asignaturas semestrales de Historia de la filosofia medieval (dos obligatorias y una optativa) en la titulación de Filosofia de la Facultat de Filosofia i Lletres. Asimismo ha profesado cursos de doctorado, entre otros, sobre Bloch, Hegel o Anselmo de Canterbury. ${ }^{7}$ De cada asignatura elaboraba a conciencia (y cada año rehacía o revisaba) materiales que entregaba a los alumnos al inicio del curso en forma de gruesos dosieres: programa, bibliografía, apuntes, resúmenes, antología de textos, comentarios de texto, esquemas detalladísimos, etc. Las tutorías con los alumnos ocupaban, asimismo, un lugar muy destacado en la programación de cada asignatura.

¿Cuáles han sido las principales aportaciones del profesor Udina, como docente e investigador, en el ámbito de la filosofía medieval ${ }^{8}$ Empezó a impartir esta materia de un modo azaroso en el curso 1978-1979 pero poco a poco se fue convirtiendo en el eje de su actividad universitaria. La ha profesado hasta su jubilación (32 cursos) y sus principales publicaciones tienen que ver con ella. Quienes le encomendaron la tarea de ocuparse de la asignatura seguramente tuvieron en cuenta sus buenos conocimientos de lenguas clásicas y su formación teológica. Efectivamente, el pensamiento medieval es inseparable de su dimensión religiosa. Udina solía dedicar una larga introducción del curso a los orígenes del cristianismo, orígenes que remiten a una doble raíz: la bíblica y la griega. En esta introducción también exponía el pensamiento patrístico griego y latino, con especial atención a Orígenes y Agustín de Hipona (y el llamado agustinismo político). El renacimiento carolingio, con Escoto Eriúgena, era el otro gran tema del primer semestre. Asimismo iniciaba el segundo quatrimestre con una introducción al Corán. Temas centrales de este semestre eran el pensamiento musulmán y el judío, Anselmo, Abelardo, Tomás de Aquino, y Ockham.

Sus clases están inspiradas en los siguientes principios — creo que en parte también se podrían aplicar a sus publicaciones - :

6 Creo que esta condición de antiguo editor explica en parte su estilo de corregir los trabajos de los estudiantes (tesis, tesinas o simples trabajos de curso): los devolvía con observaciones sobre el contenido, pero también con detalladísimas, sabias y útiles correcciones gramáticales, ortográficas y tipográficas. Los alumnos aprendían no sólo filosofía, sino a escribir correctamente. Una vez más le reitero mi agradecimiento por las observaciones, los consejos y el tiempo que, como director, dedicó a mi tesis doctoral.

Durante esta época (o después) ha traducido libros de J. Fletcher, O. Wilde, Mark Twain, J. Leita; también ha redactado estudios introductorios a la lectura de obras de W. Whitman, Dostojevskij, Cervantes o Shakespeare.

7 Ha sido el director de las tesis doctorales seguientes: Lluís Alegret, Realitat efectiva $i$ racionalitat a la ciència de la lògica de Hegel, 1990; Àngel Ros, Ontologies de la finitud, 1992; Jaume Mensa, La polèmica escatològica entre Arnau de Vilanova i els filòsofs i teòlegs professionals (1297-1305): anàlisi dels arguments i les argumentacions, 1993; Jordi Sidera, La metafísica de la creació en Ramon Llull, 2004; Joan Cortada, La filosofia de Josep M. Capdevila, 2007.

8 Véase, Josep ML. UdinA, «La enseñanza de la historia de la filosofía medieval: una experiencia de veinticinco años», en Revista Española de Filosofía Medieval 10 (2003) 199-206.

Josep Manuel Udina ha publicado estudios y/o editado obras de y sobre, entre otros autores destacados contemporáneos, Hegel, Bloch, Marcel, Joan Maragall. 
a) Lectura de las fuentes. Más que de consideraciones generales, abstractas, opiniones o especulaciones, le gustaba partir de textos concretos. Buena parte del curso giraba en torno a textos fundamentales de autores medievales. El alumno los leía en casa y el profesor Udina los comentaba en clase. Además, el alumno leía por su cuenta y daba cuenta en unas tutorías individuales de unas lecturas obligatorias, a escoger entre diversos títulos, como por ejemplo La creación del mundo de Filón de Alejandría, La consolación de la filosofía de Boecio, La ciudad ideal de Al-Farabi, etc.

b) Contextualización de los autores y los textos en su Sitz im Leben. En sus clases repetía muchas veces el aforismo «todo texto fuera de su contexto es un pretexto». Los autores, sean de la época que sean, piensan y escriben sus textos en un determinado ambiente cultural, social, político y religioso. Sin conocer este contexto es difícil, por no decir imposible, comprender sus filosofías.

c) Valoración crítica. El prof. Udina tiene una rara habilidad para buscar y encontrar los puntos fuertes y los débiles de los pensadores. Sus valoraciones siempre son muy matizadas, ponderadas y bien documentadas; allí donde muchos sólo ven luces, él descubre las sombras; y viceversa.

d) Exposición didáctica. El planteamiento de su curso y cada una de sus clases eran muy claras y pedagógicas. Sabe comunicar muy bien y el alumno siempre sabe a qué atenerse. Por si no fueran suficientes los dosieres que ofrece a principio de curso, frecuentemente, a la hora de empezar la clase, ya había llenado la pizarra de esquemas y nombres o repartía fotocopias para facilitar la comprensión de la lección.

El prof. Udina concibe la docencia y la investigación en relación mutua. Prueba de ello es que a partir del momento en que se hace cargo de la asignatura de Historia de la Filosofía Medieval sus publicaciones se ocupan principalmente de autores y temas medievales. (Dar cuenta de ellas, ni que fuera sumariamente, sería ahora demasiado prolijo). Éstos pueden ser muy variados: Agustín de Hipona, Eriúgena, Avicena, Averroes, Maimónides, Duns Escoto, el agustinismo político, la creación, las pruebas de la existencia de Dios, fe y razón, teoría y praxis, posibilidad del diálogo interreligioso, etc. etc. A pesar de ello, creo no equivocarme si afirmo que su verdadera especialidad es el pensamiento de Anselmo de Canterbury y el de Nicolás de Cusa. Ha editado, en catalán, con largas, penetrantes y bien documentadas introducciones, obras de estos dos autores ${ }^{9}$ y sobre ellos ha publicado numerosos estudios. ${ }^{10}$

De sus estudios podrían destacarse muchas cualidades, pero, aquellas que les confieren sus señas de identidad, que los hacen inconfundibles, me parece que son tres:

9 Anselm de Canterbury, Per què Déu es va fer home. Traducción e introducción de Josep Ml. Udina, (Clàssics del Cristianisme, 34), Barcelona, Proa, 1992, 218 p.; Nicolau DE Cusa, La recerca de Déu i altres escrits. Traducción e introducción de Josep Ml. UdinA, (Clàssics del Cristianisme, 82), Barcelona, Proa, 2000, 230 p.

10 A simple título de ejemplo mencionamos los siguientes: «Fe i raó: un problema no tan antic», Enrahonar, 8(1982), p. 71-80; «Textos medievals i orígens del cristianisme», Enrahonar, 19(1992), p. 55-87; «Duns Escoto y el argumento anselmiano», en DD. AA., Via Scoti. Methodologica ad mentem Ioannis Duns Scotti, Roma, Edizioni Antonianum, 1995, III, p. 783-805; «Ressonància i dissonàncies bíblico-patrístiques en l'antropologia anselmiana», en Actes del Simposi International de Filosofia de l'Edat Mitjana, Vic, Patronat d'Estudis Osonencs, 1995, p. 624633; «La «ratio fidei» medieval, entre la «revelatio» i la «debellatio»», en Acta Academiae Scientiarum, IV (1997), 133s; «Sentido y límites del «diálogo interreligioso» en el autor del Cur Deus homo», en DD. AA., Cur Deus homo (Studia Anselmiana 128), Roma, Pontificio Ateneo S. Anselmo, 1999, p. 749-765; Anselm de Canterbury (1933-1109), en P. Lluís Font (coord.), Història del pensament cristià. Quaranta figures, Barcelona, Proa, 2002, p. 259-289; «La distinción entre ratio e intellectus y la coincidentia oppositorum en Nicolás de Cusa, y sus huellas y vigencia en la modernidad», dins DD. AA., Coincidencia de opuestos y concordia. Los caminos del pensamiento en Nicolás de Cusa, Salamanca, Sociedad Castellano-Leonesa de Filosofía, 2002, p. 179-189. 
a) Familiaridad con las fuentes. Siempre habla con profundo conocimiento de causa, después de un trabajo meticuloso con las obras que son objeto de estudio.

b) Distancia crítica. Sabe encontrar el punto de vista justo: ni demasiado cerca (se pierde la noción del todo) ni demasido lejos (no es posible analizar las partes); ni con apego (es decir, sin objetividad), ni con desafección (sin interés). Como consecuencia, sus aportaciones son muy ponderadas y a la vez agudas y originales.

c) Documentación bibliográfica y diálogo con otras opiniones. Da cuenta detallada de la bibliografía sobre el tema o autor en cuestión, con abundantes notas a pie de página, y valora sus aportaciones.

Que Josep Ml. Udina i Cobo es un maestro muy especial y queridísimo por alumnos, exalumnos y colegas, quedó bien patente para todos los que pudimos asistir a su Darrera lliçó, dictada ante un abarrotado, emocionado y agradecido auditorio. Que es un maestro insustituible, lo sabe bien quien imparte ahora su asignatura. Esperemos que siga siendo este maestro que siempre ha sido, si ya no como docente en activo, sí como conferenciante en toda clase de congresos, foros y reuniones, y como investigador de la filosofía medieval.

Jaume Mensa i Valls

Profesor de Filosofia Medieval

jaume.mensa@uab.cat 